\title{
LAS GARANTÍAS DEL DERECHO FUNDAMENTAL A LA SALUD EN ESPAÑA*
}

\author{
GUILLERMO ESCOBAR **
}

\begin{abstract}
RESUMO: $\mathrm{O}$ texto trata dos diversos aspectos relacionados à garantia do direito fundamental à saúde na ordem jurídica espanhola, após expor alguns pressupostos para a compreensão da temática. É dada ênfase à proteção judicial, muito embora sejam abordados também aspectos como o direito à informação relacionado e métodos extrajudiciais de proteção. PALAVRAS-CHAVE: Direito à saúde. Direitos fundamentais. Espanha.
\end{abstract}

ABSTRACT: The text handles several aspects related to the right to health guarantee in the Spanish legal system, after introducing some premises to the topic's understanding. Emphasis is given to judicial protection, although other aspects are also dealt with, such as the related right to information and non-judicial protection mechanisms. KEYWORDS: Right to health. Fundamental rights. Spain.

SUMÁRIO: 1. Pressupostos; 2. Informação; 3. Participação; 4. Planejamento e avaliação; 5. Controle administrativo; 6. Procedimentos extrajudiciais de reclamação; 7. Controle judicial da Administração; 8. Proteção Civil e Penal; 9. Garantias Internacionais.

SUMMARY: 1. Premises; 2. Information; 3. Participation; 4. Planning and evaluation; 5. Administrative control; 6. Non-judicial demand procedures; 7. Judicial review of the Administration; 8. Civil and Criminal Protection; 9. International Guarantees.

SUMARIO: 1. Presupuestos; 2. Información; 3. Participación; 4. Planificación y Evaluación; 5. Control Administrativo; 6. Procedimientos Extrajudiciales de Reclamación; 7. Control Judicial de la Administración. 8. Protección Civil y Penal; 9. Garantías Internacionales.

\footnotetext{
* Este trabajo, cerrado en marzo de 2008, adelanta y sintetiza parte de los capítulos V y IX de la obra colectiva, dirigida por el autor, Derechos sociales y tutela antidiscriminatoria, en curso ahora de elaboración y que previsiblemente verá la luz a finales de 2008.

Abreviaturas: CDESC $=$ Comité de Derechos Económicos, Sociales y Culturales; $\mathrm{CE}=$ Constitución Española de 1978; CEDH = Convenio Europeo de Derechos Humanos; CISNS = Consejo Interterritorial del Sistema Nacional de Salud; CP = Código Penal; DA = disposición adicional; DF = disposición final; LAP = Ley de Autonomía del Paciente; LJCA = Ley de la Jurisdicción Contencioso-Administrativa; LCC = Ley de Cohesión y Calidad del Sistema Nacional de Salud; LGS = Ley General de Sanidad; LOTC = Ley Orgánica del Tribunal Constitucional; LPL = Ley de Procedimiento Laboral; OG = Observación General; PIDCP = Pacto Internacional de Derechos Civiles y Políticos; PIDESC = Pacto Internacional de Derechos Económicos, Sociales y Culturales; RD = Real Decreto; SNS = Sistema Nacional de Salud; STC $=$ Sentencia del Tribunal Constitucional; STEDH = Sentencia del tribunal Europeo de Derechos Humanos; STS = Sentencia del Tribunal Supremo; STSJ = Sentencia del Tribunal Superior de Justicia.

** Universidad de Alcalá
} 


\section{PRESUPUESTOS}

Un estudio, siquiera breve, de las garantías del derecho fundamental a la salud en España, exige algunas precisiones previas sobre las garantías de los derechos en general y sobre el contenido y límites del derecho a garantizar.

1.1. Algunas consideraciones sobre las garantías de los derechos fundamentales en general y de los derechos fundamentales sociales en particular.

En España apenas se ha teorizado sobre el concepto de garantía de los derechos fundamentales. Los tratados doctrinales y las aproximaciones generales más conocidos distinguen la cuestión de las garantías del resto de los temas de la Teoría general de los derechos fundamentales, pero no profundizan en su concepto ni en su significado (a los que parecen considerar poco problemáticos), limitándose a proponer, más que una clasificación científica de las garantías, una enumeración de las técnicas concretas de protección de los derechos en el ordenamiento español ${ }^{1}$.

De entrada, debe señalarse que el concepto de garantía es esencial al concepto de derecho fundamental, no al concepto de derecho humano ${ }^{2}$. El derecho fundamental es una categoría propia del Derecho constitucional, lo cual implica, al menos, dos garantías: vinculación del legislador y tutela judicial ${ }^{3}$, las cuales normalmente no son predicables (o al menos no son predicables de manera necesaria) de los derechos humanos. Pretender unificar los conceptos de derecho fundamental y de derecho humano en uno solo puede ser una noble aspiración pero choca demasiado con la realidad y con categorías bien asentadas en la dogmática jurídica ${ }^{4}$. En este trabajo va a hablarse exclusivamente de derechos fundamentales.

Me parece importante distinguir entre determinar el contenido de un derecho y garantizar dicho contenido. Lo primero es decidir qué inmunidades, facultades o prestaciones quedan dentro y cuáles fuera del contenido de cada figura, tarea que es preferentemente jurídica (se trata de interpretar la Constitución) pero también política, y que debe ser realizada de modo plural y abierto, dando primacía al

\footnotetext{
${ }^{1}$ Vid. L. M. DÍEZ-PICAZO, Sistema de derechos fundamentales, Thomson-Civitas, Madrid, 2003, pp. 69 y ss.; F. J. BASTIDA FREIJEDO y otros, Teoría general de los derechos fundamentales en la Constitución española de 1978, Tecnos, Madrid, 2004, pp. 196 y ss.; y S. SÁNCHEZ GONZÁLEZ (coord.), Dogmática y práctica de los derechos fundamentales, Tirant lo Blanch, Valencia, 2006, pp. 71 y ss. Por mi parte, he intentado profundizar algo más en Introducción a la teoría jurídica de los derechos humanos, Trama, Madrid, 2004, pp. 123 y ss.

${ }^{2}$ Vid. G. ESCOBAR ROCA, Introducción..., cit., esp. pp. 18-19, 27-31 y 123-124.

${ }^{3}$ Me estoy refiriendo a derechos exigibles judicialmente desde la propia Constitución, lo que I. SARLET llama derechos originarios. Vid. A eficácia dos direitos fundamentais, Livraria do Abogado, Porto Alegre,

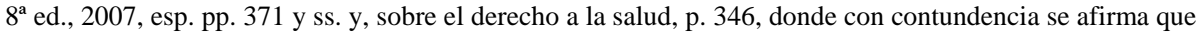
la fundamentalidad de este derecho "constituye exigencia irrenunciable de cualquier Estado (social o no) que incluya entre sus valores esenciales la humanidad y la justicia”.

${ }^{4}$ Este es, me parece, el error fundamental de FERRAJOLI, el jurista que seguramente más importancia ha otorgado al tema de las garantías. En Derechos y garantías (Trotta, Madrid, 1999) no distingue entre derechos humanos y derechos fundamentales, llegando a afirmar que los derechos reconocidos en los tratados internacionales son derechos fundamentales: si no cuentan con adecuados mecanismos de garantía no quiere decir que no sean derechos fundamentales sino que estamos ante una laguna que debe ser colmada mediante la interpretación. Esta tesis, que resulta válida para los derechos de la Constitución, no lo es, a mi juicio, para los derechos de Derecho internacional. Para más detalles, vid. mi comentario crítico a la citada obra de FERRAJOLI en Derechos y Libertades, nº 9, 2000, pp. 521 y ss.
} 
legislador y permitiendo la intervención del Tribunal Constitucional sólo de forma excepcional $^{5}$. Una vez que ha quedado claro cuál es (o cuál no es) el contenido de un derecho fundamental puede iniciarse el análisis de la vulneración. Un derecho fundamental se vulnera cuando un sujeto interviene injustificadamente sobre las inmunidades o facultades que integran su contenido o cuando no cumple, total (omisión absoluta) o parcialmente (omisión relativa), las prestaciones que el derecho requiere. Es entonces cuando entra en juego el mecanismo de las garantías.

Si la dogmática puede caminar con relativa tranquilidad en el estudio de los derechos liberales sin una clarificación del concepto de garantía, esto no sucede en relación con los derechos sociales, que aquí serán entendidos como derechos fundamentales de prestación ${ }^{6}$. A las distinciones anteriores debe añadirse otra, de especial relevancia para comprender el sentido de los derechos sociales. Los derechos liberales se cumplen con la abstención y la entrada en juego de una intervención relevante exige ya analizar si se ha vulnerado o no el derecho. Los derechos sociales se cumplen con la acción y esta raramente va a ser cuestionada: sólo de forma excepcional van a producirse omisiones absolutas o acciones insuficientes, casos en los cuales (y sólo en los cuales) puede plantearse el problema de la vulneración del derecho ${ }^{7}$. Al ser el cumplimiento y la garantía acciones estatales, algunos autores tienden a confundirlas, lo que constituye un grave error ${ }^{8}$. Llamando garantía al cumplimiento del derecho (e incluso, a veces también, a la determinación de su contenido) se diluye la naturaleza propia de los derechos sociales y se pierde de vista la importancia y la necesidad de las acciones del legislativo y del ejecutivo y sus diferencias con la labor jurisdiccional o de otros sujetos no directamente obligados a cumplir los derechos sociales.

En España todavía la doctrina mayoritaria niega la existencia misma de derechos fundamentales sociales, dada la (pretendida) falta de aplicación a los mismos de la técnica del derecho subjetivo ${ }^{9}$. En realidad, estamos en presencia de un problema interpretativo, fuertemente condicionado ideológicamente, pues las normas bien podrían dar lugar a una concepción diferente, que es la que aquí va a mantenerse ${ }^{10}$. Se trata de

\footnotetext{
${ }^{5}$ G. ESCOBAR ROCA, Introducción..., cit., pp. 81-102.

${ }^{6}$ La cuestión de las garantías de los derechos sociales siempre ha sido considerada como problemática, llegando incluso a constituir el principal leitmotiv de la Teoría de los derechos sociales. Resulta significativo que las dos aportaciones más relevantes realizadas al tema por la Dogmática constitucional española lleven en su mismo título el tema de las garantías: J. L. CASCAJO CASTRO, La tutela constitucional de los derechos sociales, CEC, Madrid, 1988 y G. PISARELLO, Los derechos sociales y sus garantías, Trotta, Madrid, 2007. Una de las obras de referencia sobre la materia, publicada en España pero escrita en Argentina, no es tampoco un análisis en profundidad de los derechos sociales sino un estudio (y desde luego, un estudio de toda solvencia) de sus garantías, especialmente de las judiciales: V. ABRAMOVICH y C. COURTIS, Los derechos sociales como derechos exigibles, Trotta, Madrid, 2002.

${ }^{7}$ Vid. R. ARANGO, El concepto de derechos sociales fundamentales, Legis, Bogotá, 2005, pp. 174 y ss.

${ }^{8}$ Yerra nuevamente FERRAJOLI, al denominar, en la obra citada, garantía primaria al cumplimiento de la obligación de legislar.

${ }^{9}$ P. ej., J. JIMÉNEZ CAMPO, “Artículo 53: protección de los derechos fundamentales”, en O. Alzaga Villamil (dir.), Comentarios a la Constitución Española de 1978, Edersa, Madrid, t. IV, 1996, pp. 519 y ss.

${ }^{10}$ Tesis que ya avancé en La ordenación constitucional del medio ambiente, Dykinson, Madrid, 1995, pp. 71-76. Por lo que conozco, sólo me ha seguido G. PISARELLO, "Derechos sociales y principio de no regresividad en España”, en C. COURTIS (comp.), Ni un paso atrás. La prohibición de regresividad en materia de derechos sociales, Ediciones del Puerto, Buenos Aires, 2007, p. 312.
} 
partir de la configuración de los derechos sociales como derechos fundamentales para, desde ahí, interpretar las posibles normas reductoras de su justiciabilidad, y no al revés.

La Constitución española (CE) incluye, en su título primero, una clasificación de derechos que los divide en tres bloques, con distinto grado de protección: el mayor corresponde a los artículos 14-29, el intermedio a los artículos 30-38 y el menor a los artículos 39-52. En los bloques mayor e intermedio se reconocen algunos derechos sociales, y singularmente el derecho a la educación, al que nadie niega la categoría de derecho subjetivo. El problema viene con los derechos sociales incluidos en el bloque de protección menor, a los cuales la doctrina mayoritaria niega la condición de derechos subjetivos y por tanto de derechos fundamentales.

Dejando fuera el medio ambiente, que dudosamente es un derecho social, en el capítulo tercero encontramos tres figuras literalmente calificadas como derechos:

"Se reconoce el derecho a la protección de la salud” (art. 43.1).

"Los poderes públicos promoverán y tutelarán el acceso a la cultura, a la que todos tienen derecho" (art. 44.1).

“Todos los españoles tienen derecho a disfrutar de una vivienda digna y adecuada” (art. 47).

Estos cuatro preceptos se ubican dentro del capítulo tercero del título primero de la CE. El capítulo tercero se intitula "De los principios rectores de la política social y económica” y el título primero "De los derechos y deberes fundamentales".

La doctrina mayoritaria aplica a la salud, cultura y vivienda la cláusula del artículo 53.3 CE, según el cual:

"El reconocimiento, el respeto y la protección de los principios rectores reconocidos en el Capítulo tercero informará la legislación positiva, la práctica judicial y la actuación de los poderes públicos. Sólo podrán ser alegados ante la Jurisdicción ordinaria de acuerdo con lo que dispongan las leyes que los desarrollan”.

Nos encontramos entonces ante una contradicción interna entre la última frase citada y otros preceptos constitucionales, sin duda más importantes: por definición (una Constitución no normativa no es una Constitución), todos los preceptos constitucionales vinculan a todos los poderes públicos, y así se desprende del artículo 9.1 ("Los ciudadanos y los poderes públicos están sujetos a la Constitución”). Por definición, si existe un derecho (y los arts. 43.1, 44.1 y 47 hablan literalmente de derecho), debe existir tutela judicial del mismo, y así lo señala el artículo 24.1 ("Todas las personas tienen derecho a obtener la tutela efectiva de los jueces y tribunales en el ejercicio de sus derechos”). Siendo esto así, caben dos posibilidades de salvar la contradicción:

a) Entender que la segunda frase del artículo 53.3 CE no se aplica a los derechos expresamente reconocidos como tales. Los artículos 43.1, 44.1 y 47 no reconocen principios sino derechos, y el artículo 53.3 sólo se aplica a los principios. Ciertamente, los artículos 43.1, 44.1 y 47 se encuentran dentro del capítulo tercero, pero también dentro del título primero, que habla de derechos fundamentales. 
b) De no aceptarse lo anterior, entender que la expresión de acuerdo con no equivale a mediante previas sino a sin contradecir. Es decir, los derechos sociales podrían exigirse, al menos en su contenido mínimo, aunque no existiera ley de desarrollo. Una vez dictada la ley de desarrollo, no podría exigirse, desde la técnica del derecho subjetivo, más de lo que da la ley, si bien la ley podría ser cuestionada desde otras técnicas de protección distintas al derecho subjetivo (p. ej., los procesos de inconstitucionalidad de la ley). Los debates constituyentes y, sobre todo, los principios específicos de la interpretación constitucional llevan a la misma conclusión ${ }^{11}$.

Para que exista un derecho fundamental debe existir un derecho subjetivo, es decir, un interés individual que puede exigirse ante los tribunales. No hay derechos fundamentales meramente objetivos. La técnica del derecho subjetivo es, por tanto, indispensable, pero ello no quiere decir que sea la única y ni siquiera la más importante. De hecho, como vamos a ver en relación con el derecho a la salud, existen otras técnicas que seguramente sean más útiles para proteger el derecho que la técnica del derecho subjetivo.

Las garantías de los derechos sociales, normalmente compatibles entre sí, pueden clasificarse como sigue:

a) Garantías directas o subjetivas, que activa el titular del derecho cuando el Estado ha incumplido sus obligaciones y aquel no ha obtenido la prestación constitucionalmente debida. Los supuestos posibles de incumplimiento son los siguientes:

- La ley no otorga prestaciones suficientes.

- Existe ley pero su falta de desarrollo reglamentario impide el otorgamiento de las prestaciones.

- Hay ley y reglamento pero el reglamento es ilegal, al prever menos prestaciones que las otorgadas por la ley.

- Hay ley y reglamento. El reglamento no es ilegal pero otorga prestaciones insuficientes, por lo que puede reputarse directamente inconstitucional.

- Hay ley y reglamento y ambos otorgan prestaciones suficientes pero uno de los dos no se cumple, bien por defectuosa interpretación bien por falta de aplicación.

Pues bien, sólo en el primer caso (sin duda, poco habitual) el titular del derecho tiene limitadas sus posibilidades de protección, pues en el Derecho español los ciudadanos no pueden recurrir directamente contra leyes inconstitucionales, limitación que vale para todos los derechos fundamentales. En estos supuestos puede solicitarse al juez que plantee la cuestión de inconstitucionalidad (art. $163 \mathrm{CE}$ ) o puede llegarse al Tribunal Constitucional mediante el recurso de amparo para que dicho Tribunal se plantee a sí mismo la cuestión de inconstitucionalidad (art. 55.2 LOTC), resolviéndola en una Sentencia posterior. En los casos de inactividad o ilegalidad reglamentarias, interpretación administrativa inconstitucional o puro o simple incumplimiento de la ley o del reglamento por la Administración, existen vías de tutela ante la jurisdicción contencioso-administrativa, previstas en la LJCA, que no es momento de detallar aquí.

${ }^{11}$ Para más detalles, G. ESCOBAR ROCA, La ordenación..., cit., pp. 73-76. 
En todos estos supuestos de incumplimiento del derecho, el afectado tiene sobre todo dos vías, que suelen entenderse como incompatibles: los tribunales ordinarios (normalmente, de la justicia contencioso-administrativa) y el Defensor del Pueblo (al resolver quejas individuales).

b) Garantías indirectas u objetivas, que no son puestas en marcha por el sujeto afectado en un caso concreto sino por otros sujetos. Normalmente actúan ante un incumplimiento generalizado e indirecto (no es necesario un ataque frontal) de un derecho, que afecta a una pluralidad de sujetos. Estas garantías son básicamente de dos tipos:

- Jurídico-coactivas: buscan la anulación de la ley o reglamento vulnerador del derecho social. En España cabe el recurso directo contra reglamentos ante la jurisdicción contencioso-administrativa, con amplia legitimación, y el recurso de inconstitucionalidad contra leyes, con legitimación muy restringida (50 parlamentarios, Presidente del Gobierno, Defensor del Pueblo, Gobiernos y Parlamentos autonómicos).

- Jurídico-políticas: entre ellas, control parlamentario de la Administración y, nuevamente, Defensor del Pueblo, que no sólo protege intereses individuales sino también colectivos (p. ej., al elaborar sus Informes anuales o monográficos).

Las formas de protección de los derechos sociales no se agotan en las previstas en el ordenamiento, que son las enumeradas hasta ahora. Paralelamente, son muy importantes las garantías políticas y sociales ${ }^{12}$. Sin una sociedad activa, con capacidad de exigir el cumplimiento de los derechos sociales fuera de los cauces previstos en la norma, seguramente los avances serán escasos.

\subsection{Breve nota sobre el contenido y límites del derecho a la salud}

El derecho a la salud (en rigor, “a la protección de la salud”), reconocido como derecho fundamental por el artículo 43.1 CE, ha sido desarrollado por ley, al menos desde 1986. La legislación vigente configura un auténtico derecho subjetivo, esto es, un derecho judicialmente exigible por los particulares, resultando por tanto inútil la polémica en torno al artículo 53.3 CE, y que en todo caso ya habíamos dejado resuelta. Así, los dos primeros párrafos del artículo 1 de la Ley 14/1986, General de Sanidad $^{13}$ (LGS), hablan, literalmente, de “derecho a la protección de la salud” y el

${ }^{12}$ Para una primera aproximación al tema, G. PISARELLO, Los derechos..., cit., pp. 115-120 y 122-128.

${ }^{13}$ El proceso de elaboración de esta primera ley de desarrollo del derecho a la salud comienza en la primera legislatura socialista, con un borrador presentado por el ministro Ernst Lluch en diciembre de 1983. Este borrador diseña un modelo sanitario totalmente novedoso en nuestro país, creando un Sistema Nacional de Salud (SNS) inspirado en el National Health Service británico y basado en cinco ejes fundamentales: la desvinculación de la asistencia sanitaria de la Seguridad Social, la superación de una concepción exclusivamente curativa de la sanidad, la universalización de la asistencia sanitaria, la unificación de la red pública y la descentralización. Debido a la presión de sectores conservadores y a divergencias dentro del propio Gobierno, la propuesta inicial socialista, especialmente hasta la aprobación, en abril de 1985, por el Consejo de Ministros del Proyecto de Ley, perdió algo de su sentido transformador originario, si bien conservó, a mi juicio, sus principales rasgos originales. En el trámite parlamentario los partidos nacionalistas lograron potenciar la descentralización del sistema (y ello hasta límites que lo alejaban del modelo británico), prestando así su apoyo a la ley. En la votación final no se obtuvo la aprobación de los grupos parlamentarios popular (por no garantizarse la libre elección de médico) y comunista (por posponerse la universalización - en el sentido de gratuidad- de la sanidad). La LGS tiene 
párrafo cuarto del mismo precepto confirma plenamente que nos hallamos ante un derecho subjetivo, al afirmar que, para su ejercicio (más exactamente, para su cumplimiento primero y para su garantía después), sus titulares "están legitimados, tanto en la vía administrativa como jurisdiccional”.

La Ley 16/2003, de Cohesión y Calidad del Sistema Nacional de Salud ${ }^{14}$ (LCC), que se mueve en una lógica algo distinta, no contiene una fórmula general de reconocimiento del derecho o de derechos asociados al mismo, sino que se preocupa tan sólo de reconocer (al menos, expresamente) aquellos derechos que considera necesarios para la cohesión del Sistema Nacional de Salud (SNS), lo que guarda relación, sobre todo, con el derecho a la igualdad (art. 4 LCC). Sin embargo, para el derecho a la salud la LCC resulta quizás más importante que la propia LGS, por cuanto concreta con una precisión antes inexistente a nivel legal el contenido de las prestaciones que cabe exigir como parte del SNS. Inicialmente, en el artículo 3.1 se hace una alusión genérica a los “derechos a la protección de la salud y a la atención sanitaria” y luego los artículos 7 a 19 detallan las prestaciones del SNS, sin que llegue a realizarse una conexión entre ambos tipos de preceptos. A mi juicio, de la interpretación sistemática (del conjunto de la LCC y de esta con la LGS) se deduce que las prestaciones del SNS forman parte del contenido del derecho fundamental subjetivo a la salud (esto es, pueden exigirse en última instancia ante los tribunales), salvo que por su contenido no quepa establecer una relación clara con la salud individual de personas concretas.

naturaleza básica (art. 2.1), salvo sus artículos 31.1 b) y c) (sobre determinadas potestades inspectoras) y 57 a 69 (sobre la organización de las Áreas de Salud), que quedan como Derecho supletorio del dictado por las Comunidades Autónomas. Paralelamente, se dictó la Ley Orgánica 3/1986, por entenderse que las materias en ella reguladas estaban reservadas a este tipo normativo. Casi todo su contenido afecta, de una otra forma, al derecho a la salud. Así se señala en el artículo 1.1 de la propia Ley, que concreta su objeto en "la regulación general de todas las acciones que permitan hacer efectivo el derecho a la protección de la salud reconocido en el artículo 43 y concordantes de la Constitución”. La LGS ha sido objeto de un desarrollo normativo suficiente y de un grado de aplicación, a grandes rasgos, bastante satisfactorio. La sanidad no se ha convertido en un campo habitual de confrontación radical o global entre los principales partidos y la bonanza económica de los últimos años ha hecho posible la separación definitiva entre sanidad y Seguridad Social, así como un desarrollo importante de la red asistencial y de las prestaciones sanitarias públicas. Hoy se sigue considerando a la LGS como uno de los pilares normativos fundamentales del Estado social español.

${ }^{14}$ Los más de 16 años transcurridos desde la entrada en vigor de la LGS llevaron a la necesidad de adaptarla a la evolución posterior, especialmente de cara a la configuración de un sistema sanitario de hecho modificado tras la fuerte (y ya concluida, en el momento de presentarse el proyecto) descentralización acaecida. El proyecto de ley, presentado por el segundo Gobierno del Partido Popular en noviembre de 2002, fue aprobado, tras un rápido y fructífero debate parlamentario (se tuvieron en cuenta buena parte de las enmiendas presentadas), por unanimidad de las Cámaras. La LCC modifica partes importantes de la LGS y regula un variopinto conjunto de cuestiones (lo que se demuestra, p. ej., en la relación, contenida en su art. 2, de los principios que la informan), con importantes novedades en materias como la función estatal de coordinación general de sanidad, el Consejo Interterritorial del Sistema Nacional de Salud (CISNS) o la financiación sanitaria. La fijación de las prestaciones sanitarias es la aportación más trascendente de la Ley para el derecho a la salud. El Real Decreto 1030/2006, de 15 de septiembre, por el que se establece la cartera de servicios comunes del Sistema Nacional de Salud y el procedimiento para su actualización (RDCSC) desarrolla el alcance de las prestaciones sanitarias, y tiene por tanto una trascendencia constitucional evidente. La LCC tiene en su mayoría carácter básico (DF $1^{\mathrm{a}}$ ), si bien un buen número de preceptos no admite desarrollo autonómico, bien por ser dictados en ejercicio de competencias exclusivas, bien por ser de aplicación únicamente a la Administración General del Estado. 
Estructuralmente, el derecho a la salud es, ante todo, un derecho de prestación, en el sentido amplio del término (derecho a prestaciones fácticas y derecho a una determinada organización) ${ }^{15}$. Contiene también una faceta defensiva, de menor relevancia para la imagen típica la figura y a la que no me referiré en el presente trabajo.

La determinación del contenido del derecho ha sido realizada básicamente por la LGS y la LCC, pero estos y otros textos deben ser confrontados con la Constitución, pues podría darse el caso de que la ley hubiera dotado al derecho de un contenido o de unas garantías inferiores a las exigidas por la norma suprema. Además, la ley debe ser interpretada de conformidad con la Constitución, y ello exige saber previamente lo que la Constitución impone. Para la determinación del contenido constitucional del derecho se hace preciso conocer el bien jurídico protegido ${ }^{16}$, en nuestro caso, la salud. El derecho a la salud tiene un alcance, en principio, finalista: como regla general, no puede exigirse la salud como tal (algo muchas veces imposible para la acción humana) sino más bien que se realicen acciones en su favor (obligación de medios), aunque en ocasiones pueden exigirse también resultados; piénsese sobre todo en los casos de enfermedades claramente susceptibles de curación.

La salud, como objeto del derecho a la salud, no es un concepto típicamente jurídico, sino en parte científico, en parte cultural y en todo caso histórico. La dogmática tiene el deber de dar cuenta de las definiciones al uso y de adaptarlas a un ordenamiento jurídico concreto, que tiene su propia lógica. Debe partirse al respecto, como resulta habitual, de la conocida declaración de la Organización Mundial de la Salud, que en su norma constitutiva, de 1946, definió a la salud como el "estado de completo bienestar físico, mental y social y no solamente la ausencia de enfermedades y dolencias". Parece claro, y así lo reconoce con rotundidad la doctrina, que esta definición no resulta sin más aplicable al Derecho español, ya que incluye bienes no protegidos por el artículo 43 sino por otros preceptos de la CE (en general, los llamados condicionantes de la salud) y porque alude a un objetivo que no cabe pretender constituya una finalidad abarcable por el Derecho y la acción del Estado. Aquí tiene razón el dicho “quien mucho abarca, poco aprieta”. Desde la Medicina, todas las definiciones remiten a un estado de normalidad orgánica y funcional, delimitado negativamente como la ausencia de enfermedad. En esta dirección, la definición más precisa y exigente que encontramos en nuestro ordenamiento (y la que tomaremos como referencia en este capítulo) se encuentra en el artículo 20.3 LCC, el cual, a la hora de fijar criterios para la incorporación de nuevas prestaciones al SNS, viene a señalar que la salud guarda relación, negativamente, con la ausencia de enfermedades, dolor y sufrimiento y, positivamente, con la esperanza de vida y con la autonomía personal. En definitiva, tener salud implica vivir los años deseados, sin necesidad de ayuda de otras personas y desprovisto de enfermedades, dolor y sufrimiento (en estos dos últimos casos, en el sentido sanitario de la expresión). Estos elementos deben ponerse en conexión con la idea de protección, pues el derecho fundamental no incluye cualesquiera medidas encaminadas a evitar la enfermedad, el

${ }^{15}$ R. ALEXY, Teoría de los derechos fundamentales, CEC, Madrid, 1993, pp. 419 y ss.

${ }^{16}$ Con carácter general, M. CORNILS, Die Ausgestaltung der Grundrechte, Mohr, Tubinga, 2005, pp. 596 y ss. 
dolor o el sufrimiento o a promover la esperanza de vida o la autonomía sino únicamente las medidas sanitarias.

Los elementos que integran la definición de salud (y en especial los términos enfermedad, dolor y sufrimiento) remiten, como adelantaba, a consideraciones científicas, pero también culturales y por tanto históricas. No es igual, por ejemplo, la concepción del sufrimiento de una u otra cultura o de uno u otro momento histórico dentro de la misma cultura. Sin embargo, no cabe caer en un relativismo cultural, pues existe un mínimo común denominador que, dentro de las pautas dominantes en nuestro entorno, permite objetivar en alta medida el concepto de salud. Desde esta perspectiva, tal y como sucede con la mayor parte de los derechos sociales, cabe apreciar una tendencia a la ampliación progresiva del concepto de salud, pues cada vez son mayores no sólo los conocimientos científicos (lo que antes se consideraba una molestia sin trascendencia es ahora calificado de enfermedad) sino también los anhelos y exigencias de bienestar de la sociedad. Por cuanto la salud tiene mucho de concepto abierto y por cuanto la salud resulta ser la antesala de la determinación del contenido del derecho a la salud (las acciones que van a exigirse son aquellas necesarias para la protección del bien jurídico y no otras), se impone un diálogo colectivo para definirla en cada momento: no sólo el Parlamento y la Administración (y el personal sanitario a su servicio) tienen algo que decir sobre qué es enfermedad, dolor o sufrimiento o sobre qué grado de autonomía debe tener una persona o cuántos años debe vivir sino también las sociedades científicas y la llamada sociedad civil deben pronunciarse al respecto, lo que exige adecuados foros de participación.

La salud como bien jurídico-constitucional es única, pues en última instancia mira siempre hacia el interés de personas concretas. A mi entender, las expresiones “salud" del artículo 43.1 CE y "salud pública” del artículo 43.2 no aluden a objetos distintos sino a uno solo, que puede protegerse de dos maneras distintas ${ }^{17}$ :

a) La protección de la salud individual abarca el conjunto de acciones dirigidas a tutelar la salud (esto es, conservar la vida, favorecer la autonomía y eliminar o paliar la enfermedad, el dolor y el sufrimiento) de personas concretas en casos concretos, normalmente a solicitud de estas. Los dos componentes típicos del contenido del derecho, entendido en este sentido, son la asistencia sanitaria y, como prolongación de esta, el derecho al medicamento.

b) La protección de la salud pública (también llamada colectiva) abarca el conjunto de acciones (en su mayoría preventivas), dirigidas igualmente a tutelar la salud, en el sentido antes indicado, pero al margen o con independencia de la situación concreta de personas concretas. Como es habitual, la determinación de las acciones que integran esta forma de protección es más difusa que en el caso anterior, pero hoy día la normativa internacional y los antecedentes históricos (recordemos que el Estado se preocupó antes de proteger la salud colectiva -policía sanitaria- que la salud individual -asistencia sanitaria-) permiten dibujar un conjunto bastante diferenciado y consolidado de actuaciones sobre las que difícilmente cabría marcha atrás,

${ }^{17}$ Por todos, C. CIERCO SEIRA, Administración pública y salud colectiva, Comares, Granada, 2006, p. 8. 
conformando así una suerte de garantía institucional de la salud pública, ahora consolidada por obra del artículo 43.2 $\mathrm{CE}^{18}$.

Como regla general, la protección de la salud individual configura el contenido del derecho fundamental subjetivo y la protección de la salud pública el carácter meramente objetivo de dicho derecho fundamental. Sin embargo, hay también algunas excepciones o supuestos de intersección (acciones en defensa de la salud pública que forman parte del contenido del derecho a la salud estrictamente considerado).

Existe por tanto una parte del derecho fundamental que es meramente objetiva: sirve a los mismos intereses (la protección de la salud, que en última instancia es siempre salud individual) pero no siempre puede ser exigida ante los tribunales; desde otra perspectiva, puede afirmarse que forma más bien parte de las garantías (objetivas) del derecho y no tanto de su contenido. Así sucede con la parte sustancial de la política de salud pública ${ }^{19}$. Esta política, que cabe definir como aquella destinada a la prevención y control de enfermedades al margen de la asistencia sanitaria concreta $^{20}$, forma parte de las prioridades de la LGS y de la LCC y se concreta en un amplio y variado conjunto de obligaciones de la Administración, cuya vinculación jurídica resulta sin embargo bastante relativa ${ }^{21}$. Entre ellas cabe citar la realización de estudios epidemiológicos y la planificación y evaluación sanitaria, basándose en "un sistema organizado de información sanitaria, vigilancia y acción epidemiológica" (art. 8.1 LGS), la educación sanitaria (exigida ya por el art. $43.3 \mathrm{CE}$ ), considerada “elemento primordial para la mejora de la salud” (art. 18.1), la difusión de la información epidemiológica "para fomentar el conocimiento detallado de los problemas de salud" (art. 18.13) y el fomento de la investigación científica en salud (arts. 18.15 y 106-110). El artículo 65 LCC establece también obligaciones importantes, desprovistas sin

${ }^{18}$ A título de ejemplo, pueden citarse las actuaciones en tres ámbitos concretos: a) Campañas de vacunación, cada vez más exigentes, articuladas en torno a los calendarios de vacunación aprobados por el CISNS. b) La drogadicción. Además de los tipos penales relacionados con la droga y de la amplia labor policial y judicial que ello conlleva, el Delegado del Gobierno para el Plan Nacional sobre Drogas, dependiente del Ministerio, ejecuta un amplio Plan de carácter transversal pero centrado fundamentalmente en la prevención, mediante actuaciones de muy diverso signo. c) El tabaquismo. La reciente Ley 28/2005, de Medidas Sanitarias contra el Tabaquismo, ha supuesto un cambio radical en la lucha contra este problema. Como medida más llamativa, se ha tipificado como infracción administrativa el consumo de tabaco en los centros de trabajo, así como en los establecimientos abiertos al público, salvo en determinados establecimientos de mayor dimensión y, en todo caso, en las zonas habilitadas al efecto.

${ }^{19}$ La LCC incluye algunas acciones en materia de salud pública que creemos forman parte del derecho subjetivo a la salud (sobre todo, art. 12.2 c) y d), desarrollado por los apartados 3 y 4 del Anexo II del RDCSC). La conversión de obligaciones administrativas en contenido del derecho subjetivo está más clara en algunas leyes autonómicas.

${ }^{20}$ Hacemos esta precisión conceptual, pues la legislación utiliza con frecuencia un concepto muy amplio de salud pública, que prácticamente la identifica con la salud sin más. Por otra parte, uno de las finalidades principales de la LGS, no conseguida del todo, fue integrar las medidas preventivas en el ámbito de la asistencia sanitaria individual (p. ej., arts. 12.1 y 13.1 LCC), en cuyo caso nos encontraríamos fuera, a mi entender, del concepto típico de salud pública.

${ }^{21}$ P. ej., ninguna de las carencias de la sanidad española, que habitualmente se critican (p. ej., V. NAVARRO, El subdesarrollo social en España, Anagrama, Barcelona, 2006, pp. 50-59) sería fácilmente superable mediante la mera invocación de los mandatos constitucionales aplicables, al margen de la lógica de los derechos subjetivos. Desde luego, no cabe descartar (y resulta recomendable como estrategia procesal) la exigencia ante los tribunales de obligaciones legales de la Administración, por la vía del art. 43.1 CE. 
embargo de sanciones en caso de incumplimiento; no es de extrañar, por ello, que no siempre haya llegado a adoptarse una práctica plenamente coherente con los principios legales. No hay que olvidar, sin embargo, el valor añadido de esta normativa (desarrollo, en definitiva, del art. 43.2 CE) como límite o justificación de las intervenciones sobre derechos fundamentales (incluyendo el mismo derecho a la salud, en su faceta individual), algo ya previsto por el PIDCP y el CEDH, lo que en última instancia redunda en beneficio de la salud individual, habida cuenta de que, como sabemos, el bien jurídico protegido es el mismo.

El contenido prestacional del derecho a la salud se divide a su vez en dos grandes elementos: la asistencia sanitaria y el medicamento ${ }^{22}$. La primera comprende disponibilidad de establecimientos y personal adecuados, accesibilidad física y económica, extensión suficiente (cartera de servicios), integridad, continuidad y celeridad (asistencia en un período de tiempo razonable). El segundo comprende el acceso a los medicamentos derivados de la asistencia médica, en condiciones de asequibilidad.

Tras el examen de la amplia y compleja normativa española de desarrollo de los derechos a la asistencia sanitaria y al medicamento, sólo se aprecian supuestos excepcionales de omisión absoluta de regular o de leyes o reglamentos cuya constitucionalidad es dudosa, normalmente por dos motivos principales: retroceso injustificado o diferencias de trato no justificadas. Estas intervenciones, que no es este el momento de exponer, tienen un carácter general; en relación con las consideradas inconstitucionales, una vez realizadas las modificaciones normativas oportunas, dejarían de existir. Sin embargo, las intervenciones que suscitan con mayor frecuencia las reclamaciones de los ciudadanos ${ }^{23}$ y que tienen un carácter permanente (dada la gran amplitud de sus posibles autores y de sus formas de aparición) son las que proceden de los particulares y, sobre todo, de las Administraciones sanitarias (incluyendo el personal sanitario dependiente del SNS), en su faceta de creadoras de actos administrativos y otorgantes de prestaciones organizativas, financieras y materiales.

Como las intervenciones no normativas sobre la faceta prestacional del derecho a la salud pueden ser muy variadas, nos contentaremos con señalar el método de análisis de su constitucionalidad, con especial atención a los límites que más frecuentemente se oponen al derecho a la salud. La amplísima variedad de intervenciones posibles, a la vista de las reclamaciones planteadas ante el Defensor del Pueblo y ante los tribunales, se reduce, en su mayoría (la casuística es, por supuesto, mucho más rica) a dos grandes tipos de supuestos:

- Por parte de la Administración sanitaria, falta de disponibilidad o de celeridad suficientes, en cuyo caso lo habitual es que el ciudadano acuda a otro centro sanitario

\footnotetext{
${ }^{22}$ La enumeración de prestaciones que sigue, que no puede ser explicitada aquí, se inspira en la OG núm. 14, del Comité DESC, ampliada y adecuada a las peculiaridades del Derecho español.

${ }^{23}$ Debe destacarse, sin embargo, que también en los supuestos de inconstitucionalidad normativa que puedan detectarse cabría reclamación individual: en los casos de leyes inconstitucionales, solicitando al juez el planteamiento de la cuestión de inconstitucionalidad; en el caso de los reglamentos inconstitucionales, solicitando su nulidad ante la jurisdicción contencioso-administrativa y en los casos de omisión reglamentaria, exigiendo la adopción del reglamento correspondiente ante esta misma jurisdicción.
} 
y exija después el reintegro de los gastos ocasionados, en las circunstancias en las que ello es legalmente posible en el momento actual (sobre todo, urgencia vital y agotamiento de los plazos de espera previstos en determinadas Comunidades Autónomas). En estos casos (que son los que suelen llegar a los tribunales pero que sólo suponen una pequeña parte de las intervenciones que se producen en la realidad), la intervención se materializa en el acto administrativo que rechaza el reintegro. A mi juicio, ningún límite constitucional puede justificar estas intervenciones: la Administración no puede escudarse en razones presupuestarias para negarse a prestar la asistencia sanitaria necesaria para garantizar el bien protegido por el artículo 43.1 CE.

- Por parte del personal sanitario adscrito al SNS, negativa al tratamiento médico (rechazo inicial del paciente, no envío al especialista, no envío a un centro de referencia, negativa a prescribir los medicamentos adecuados, alta no consentida) o tratamiento médico deficiente, inferior a los parámetros exigidos por la lex artis ad hoc. Normalmente, el paciente reclama, por la vía de la responsabilidad patrimonial, tras sufrir un daño a su salud, muchas veces ya irreparable. En estos supuestos (haya o no daño) nos encontramos ante una intervención fáctica (no ante un acto administrativo), consistente en un determinado comportamiento médico, que presenta formas variadas (desde una mera negativa verbal hasta una constancia en la historia clínica). Tampoco creo que exista aquí límite constitucional alguno que pueda justificar la negativa al tratamiento.

Tras estas breves consideraciones generales sobre el derecho a la salud en el Derecho español, paso a describir el sistema de garantías propio de este derecho (en la visión reduccionista que estamos siguiendo: sólo como derecho de prestación), dejando fuera las garantías aplicables a todos los derechos fundamentales y que pueden encontrarse en cualquier manual de Derecho constitucional español. De entrada, advierto que voy a realizar una exposición, además de sintética (se trata de ofrecer un panorama general, sin entrar en los detalles), de un tono preferentemente jurídicodescriptiva, con muy escasas alusiones (aunque alguna se hará) a la utilización y utilidad real de las garantías desde el punto de vista sociológico.

\section{INFORMACIÓN}

La información recorre, en múltiples y variadas manifestaciones, toda la legislación sanitaria española. Desde la perspectiva estricta de la garantía del derecho a la salud ${ }^{24}$, como derecho prestacional $^{25}$, interesa destacar dos grupos de estas manifestaciones.

\footnotetext{
${ }^{24}$ El diagnóstico queda fuera de este apartado, pues no es una garantía del derecho a la salud sino una prestación que forma parte de su contenido (art. 12.2 b) y 13.2 e) LCC y apartados 2.1 y 5, respectivamente, de los Anexos II y III del RDCSC).

${ }^{25}$ El derecho a la información sobre la propia enfermedad sirve como instrumento para el mejor ejercicio de la libertad de opción incluida en la faceta defensiva del derecho a la salud pero que no agota con ello su finalidad. Según los artículos 4 y 5 de la Ley 41/2002, de Autonomía del Paciente (LAP), los pacientes tienen derecho a ser informados, de modo comprensible y adecuado a sus necesidades, por parte del médico responsable, de la finalidad y la naturaleza de cada intervención, sus riesgos y sus consecuencias. Este derecho puede limitarse al paciente en el llamado estado de necesidad terapéutica, esto es, "cuando por razones objetivas el conocimiento de su propia situación pueda perjudicar su salud de manera grave”. Por su parte, se reconocen los derechos de acceso a la historia clínica, salvo cuando afecte a la confidencialidad
} 
a) Derecho a la información sobre los servicios sanitarios, como instrumento para la mejor solicitud de los contenidos prestacionales del derecho a la salud. En general, todo ciudadano tiene derecho a la información sobre los servicios sanitarios disponibles, sobre su calidad y sobre sus requisitos de acceso (arts. 9 y 10.2 LGS, 7.2 y 26 LCC, 12.1 LAP y 12 RDCSC); en garantía de ello, se obliga a los servicios de salud a disponer de "una guía o cartera de los servicios en la que se especifiquen los derechos y obligaciones de los usuarios, las prestaciones disponibles, las características asistenciales del centro o del servicio, y sus dotaciones de personal, instalaciones y medios técnicos" (art. 12.2 LAP), así como a regular "los procedimientos y los sistemas para garantizar” el derecho a la información (art. 12.3 LAP). También se reconoce la llamada información epidemiológica, prevista ya por el artículo 8.1 LGS y definida como el derecho "a conocer los problemas sanitarios de la colectividad cuando impliquen un riesgo para la salud pública o para [la] salud individual” y a que esta información sea difundida (arts. 18.13 LGS y 6 LAP).

b) Información recopilada por el SNS, como medio necesario para la mejora de la normativa y de la política sanitaria, lo que indirectamente favorece, al modo de garantía objetiva, al derecho a la salud. Los instrumentos de información, previstos ya en la LGS (arts. 23, 40.13 y 16, 73.1 y 77.3, entre otros), se potencian y desarrollan en la LCC; aunque existen referencias a la información a lo largo de esta última, las mismas estas se concentran sobre todo en el capítulo $\mathrm{V}$, relativo al sistema de información sanitaria, que incluye una amplia relación de obligaciones públicas, dirigidas, entre otras cosas, a responder las necesidades de los ciudadanos (art. 53.1). El acceso público al sistema de información sanitaria se hace depender de un acuerdo del CISNS (art. 53.4), que hasta ahora no se ha producido.

\section{PARTICIPACIÓN}

En desarrollo del artículo 129.1 CE, el artículo 5.1 LGS señala que "Los Servicios Públicos de Salud se organizarán de manera que sea posible articular la participación comunitaria a través de las Corporaciones territoriales correspondientes en la formulación de la política sanitaria y en el control de su ejecución”, precisando el párrafo siguiente que "a los efectos de dicha participación se entenderán comprendidas [entendemos que no con carácter exclusivo] las organizaciones empresariales y sindicales”. Advierto de entrada un claro sesgo corporativista en la opción del legislador (que posteriormente se diluye en el art. 53.1, que más correctamente habla de "criterios de participación democrática de todos los interesados”), así como una previsión ciertamente extraña, pues no se entiende bien qué papel pueden tener las organizaciones empresariales en la participación en un sector ajeno a sus intereses ${ }^{26}$. De hecho, la propia LGS olvida después a estas organizaciones, al regular los órganos concretos de participación.

La regla organizativa precitada es concretada por la propia LGS mediante la creación de los Consejos de Salud, que básicamente pueden ser de dos tipos:

de tercero o al "derecho de los profesionales en su elaboración, los cuales pueden oponer al derecho de acceso la reserva de sus anotaciones subjetivas” (art. 18 LAP), y de obtención de "certificados acreditativos” del propio estado de salud (arts. 20 LAP y 10.2 RDCSC).

${ }^{26}$ A no ser en el ámbito de la salud laboral, regulado en los arts. 21-22. 
a) Consejos de Salud de cada Comunidad Autónoma, a cuya creación obliga el artículo 53.2 $\mathrm{LGS}^{27}$. Se han diseñado a semejanza de los Consejos de Salud de Área, a los que me referiré seguidamente, si bien con una composición más plural, abierta a las asociaciones de usuarios, aunque de forma minoritaria.

b) Consejos de Salud de Área de Salud, regulados por el artículo 58 LGS, supletorio de la normativa autonómica. Según la normativa estatal, son de obligatoria constitución por las Comunidades Autónomas (art. 53.2 LGS) y están formados por representantes de las entidades locales (el 50\%), de los profesionales sanitarios titulados pertenecientes a los sindicatos más representativos (al menos, el 25\%) y por la Administración sanitaria del Área de Salud (el resto). Diseñados como órganos de asesoramiento y, sobre todo, de control (p. ej., son informados del anteproyecto del Plan de Salud y de la Memoria anual del Área y verifican "la adecuación de las actuaciones en el Área de Salud a las normas y directrices de la política sanitaria y económica”), no han llegado a implantarse en la práctica.

La LCC, que tiene entre sus objetivos regular la participación en el ámbito sanitario (arts. 1 y 5 i), además de referirse a la misma en ámbitos concretos, como los recursos humanos (art. 35.3), la investigación (art. 45.3 b), el sistema de información sanitaria (art. 53.1 d) o la salud pública (art. 66 e), crea un nuevo órgano de participación de ámbito nacional y tres mecanismos más, de carácter potestativo:

a) El Comité Consultivo del SNS, órgano dependiente del CISNS, presidido por el ministro de Sanidad y Consumo y formado por seis representantes de la Administración General del Estado, seis de las Comunidades Autónomas, cuatro de la Administración local, ocho de las organizaciones empresariales (nuevamente, desconozco con qué fin) y ocho de los sindicatos más representativos de ámbito nacional. Tiene como funciones informar, asesorar y formular propuestas sobre materias "de especial interés para el funcionamiento del [SNS]", entre ellas los proyectos normativos que afecten a las prestaciones sanitarias y las disposiciones del CISNS relacionados con los derechos de los pacientes (art. 67.2 LCC). En la práctica, el Comité Consultivo no está desempeñando sus funciones.

b) El Foro Abierto de Salud es un mecanismo que se pone en marcha con carácter temporal por iniciativa del Ministerio de Sanidad y Consumo, cuando este lo juzgue conveniente y con la composición que "en cada momento se determine" (entendemos, que también por decisión del Ministerio), que puede invitar al afecto a “organizaciones, consejos, sociedades o asociaciones”, "para el estudio, debate y formulación de propuestas sobre temas específicos que en un determinado momento tengan impacto en el [SNS]” (art. 67.3 LCC). No se conoce de la creación de ningún Foro Abierto de Salud.

c) Un enigmático Foro Virtual, del que el artículo 67.4 LCC únicamente dice que "se mantendrá a través de la red informática". No se tiene noticia de su creación.

d) Las redes de conocimiento, que pueden ser creadas por las Administraciones sanitarias, para generar y transmitir conocimiento científico y favorecer la participación

${ }^{27}$ Más ambiguamente, el art. 53.3 LGS señala que "En ámbitos territoriales diferentes [a la Comunidad Autónoma y al Área de Salud], la Comunidad Autónoma deberá garantizar una efectiva participación”. 
social, “como plataforma de difusión de la información, intercambio de experiencias y como apoyo a la toma de decisiones a todos los niveles del [SNS]" (art. 68.1 LCC). No se conoce de la creación de ninguna red de esta naturaleza. Paralelamente, el artículo 68.2 obliga a crear una infraestructura de comunicaciones, entendemos que como mecanismo de apoyo a las redes de conocimiento que eventualmente se pongan en marcha.

En síntesis, nos encontramos, por un lado, con tres tipos de órganos de asesoramiento y control, dominados por representantes de la Administración local, sindicatos y organizaciones empresariales, cuya actuación y resultados apenas se conocen; por otro, con mandatos y habilitaciones de participación que no han sido desarrollados. El fracaso del legislador es casi absoluto en este punto, por lo que debería reflexionarse sobre el acierto del diseño legal.

A mi juicio, los instrumentos de participación deberían servir, entre otras cosas, como instrumento de garantía del derecho a la salud (se gana legitimidad y se reducen los litigios $^{28}$ ) y este cometido, con el actual diseño legal, se revela muy dificultoso ${ }^{29}$. La participación queda reducida al asesoramiento y al control y encorsetada en órganos que por su composición mayoritaria no favorecen los intereses de los usuarios (sus intereses o son otros o no son específicos del sector), faltando voluntad política para poner en marcha otros mecanismos legalmente previstos, como el Foro Abierto de Salud, el Foro Virtual o las redes de conocimiento. Sería deseable que se ampliaran las posibilidades de participación institucional de las organizaciones no gubernamentales en general y de las asociaciones de usuarios de la sanidad en particular, yendo más allá de las tímidas previsiones de la normativa autonómica, pero lo cierto es que tampoco parece existir demasiada presión al respecto. Tampoco se han ejercitado apenas los derechos previstos en la legislación administrativa general ni se han aprovechado las posibilidades de participación no corporativa abiertas (bien que de forma bastante retórica) por algunas casi todas las leyes autonómicas.

\section{PLANIFICACIÓN Y EVALUACIÓN}

La progresividad y efectividad del derecho a la salud exigen una constante actividad de planificación y evaluación administrativa, que sirve de garantía objetiva al derecho a la salud. La LGS prevé la formulación de un plan integrado de salud, compuesto por el plan nacional de salud y los planes homólogos de las Comunidades Autónomas (arts. 70-77). Sin embargo, no ha llegado a aprobarse ninguno a nivel nacional. La LCC, por su parte, prevé la formulación por el CISNS de planes integrales de salud sobre enfermedades concretas (art. 64), habiéndose adoptado planes sobre la cardiopatía isquémica, el cáncer y la obesidad, nutrición y actividad física.

En cuanto a la calidad, el artículo 69 LGS y los artículos 59 a 63 LCC establecen una serie de obligaciones administrativas, repartidas entre diversos órganos,

\footnotetext{
${ }^{28}$ Más argumentos en N. DANIELS y J. SABIN, "Limits to Health Care: Fair Procedures, Democratic Deliberation and the Legitimacy Problem for Insures”, Philosophy and Public Affairs, vol. 26, n 4, 1997, pp. 347-348.

${ }^{29}$ Otros apuntes en esta dirección en M. GUTIÉRREZ SASTRE, La participación en los servicios públicos de bienestar, CES, Madrid, 2005, pp. 98-100.
} 
como la Agencia de Calidad del SNS (elaborar y mantener una "infraestructura de la calidad”, formada por normas de calidad y seguridad, indicadores, guías de práctica clínica y asistencial y registro de buenas prácticas y de acontecimientos adversos), el CISNS (elaborar periódicamente planes de calidad), el Ministerio de Sanidad y Consumo y sus homólogos autonómicos (elaborar planes de calidad ${ }^{30}$ y fomentar la evaluación externa y periódica de la calidad y la seguridad de los centros y servicios sanitario mediante auditorías independientes) y el Observatorio del SNS (elaborar estudios comparados de los Servicios autonómicos de Salud y un Informe anual sobre el estado del SNS).

\section{CONTROL ADMINISTRATIVO}

Como garantía preventiva y fundamentalmente objetiva del derecho a la salud, la Administración está obligada a llevar a cabo tareas permanentes de control de las actividades potencialmente peligrosas para la salud y del mismo sector sanitario, utilizando las típicas técnicas de la policía administrativa ${ }^{31}$, como la autorización, prevista con carácter general en el artículo 25.1 LGS, o la inspección de los centros y establecimientos sanitarios, públicos y privados (art. 30.1 LGS). Ambas tareas son concretadas por la legislación autonómica y llevadas a cabo por las Administraciones sanitarias autonómicas.

La Alta Inspección, por su parte, regulada en los artículos 76 a 79 LCC, es ejercida por los órganos estatales competentes en materia de sanidad, para la "garantía y verificación del cumplimiento de las competencias estatales y de las Comunidades Autónomas en materia de sanidad y de atención sanitaria” del SNS, lo que evidentemente incluye el control del cumplimiento del derecho a la salud ${ }^{32}$.

En última instancia, la Administración cuenta con la posibilidad de imponer sanciones. Con carácter general, cabe citar al respecto buena parte de los tipos sancionadores propios de la legislación de consumo (sobre todo, art. 34 Ley 26/1984) y, con carácter específico, el artículo 35 LGS, dirigido sobre todo a los centros sanitarios privados y escasamente utilizado, dada su inconcreción ${ }^{33}$. Más específicamente, el Derecho disciplinario castiga diversas conductas de los profesionales sanitarios, siendo la salud el bien jurídico implícitamente protegido por alguno de los tipos correspondientes (art. 72 LEMPE); paralelamente, los colegios profesionales pueden imponer sanciones en caso de incumplimiento de los deberes propios de la deontología sanitaria (art. 63 RD 1018/1980). Parte de la escasa jurisprudencia recaída sobre

\footnotetext{
${ }^{30}$ El Ministerio de Sanidad y Consumo publicó en marzo de 2006 un Plan de Calidad para el SNS, entre cuyos contenidos figuran la protección y promoción de la salud y la prevención, fomentar la equidad y mejorar la atención a los ciudadanos utilizando las tecnologías de la información, propósitos todos ellos que sirven a la garantía objetiva del derecho a la salud.

${ }^{31}$ Más ampliamente, C. CIERCO SEIRA, Administración..., cit., pp. 188-193.

${ }^{32}$ La utilidad de la Alta Inspección para garantizar el derecho a la salud, anunciada ya en la STC 32/1983, apenas ha sido explorada. Un leve apunte en J. J. SOLOZÁBAL ECHAVARRÍA, Bases constitucionales de una posible política sanitaria en el Estado autonómico, Fundación Alternativas, Madrid, 2006, p. 39. Bien es cierto que con la configuración actual de la Alta Inspección las posibilidades reactivas no son muchas; vid., al respecto, M. REBOLLO PUIG, “La Alta Inspección”, en L. Parejo, A. Palomar y M. Vaquer (coords.), La reforma del Sistema Nacional de Salud, Marcial Pons, Madrid, 2004, pp. 159-166.

${ }^{33} \mathrm{El}$ art. 35 se encuentra tan plagado de tipos sancionadores en blanco que raya la inconstitucionalidad.
} 
sanciones en materia sanitaria utiliza el artículo 43.1 CE como criterio interpretativo, normalmente para confirmar la legalidad de la sanción impuesta por la Administración.

\section{PROCEDIMIENTOS EXTRAJUDICIALES DE RECLAMACIÓN}

Con el fin de evitar el recurso a la vía judicial, el artículo 10.12 LGS reconoce el derecho de toda persona a "utilizar las vías de reclamación y de propuesta de sugerencias en los plazos previstos. En uno u otro caso deberá recibir respuesta por escrito en los plazos que reglamentariamente se establezcan”. Por su parte, el artículo 12.2 LAP establece que se "facilitará a todos los usuarios información sobre [...] sugerencias y reclamaciones”. No existe normativa estatal de desarrollo de estas previsiones.

Los procedimientos extrajudiciales de reclamación han sido desarrollados por la normativa autonómica, en la cual encontremos tres modelos de regulación:

a) Presentación de reclamaciones ante cada centro sanitario: Castilla y León (art. 26 Ley 8/2003), Navarra (Decreto 204/1994) y País Vasco (Decreto 175/1989). La normativa navarra es la más garantista, al incluir la obligación de respuesta al ciudadano en un plazo no superior a 20 días.

b) Presentación de reclamaciones ante una Oficina directamente dependiente de la Consejería competente en materia de sanidad: Cantabria (art. 56 Ley 7/2002) y Canarias (art. 12.6 Ley 11/1994), esta última con una regulación muy detallada del contenido de la contestación al ciudadano (art. 16.1 del Decreto 94/1999).

c) Creación de un Defensor del Paciente o Usuario de los servicios sanitarios públicos de la Comunidad Autónoma, para la defensa del derecho a la salud frente a la Administración sanitaria autonómica. Las Comunidades Autónomas que lo prevén han dictado normativas relativamente dispares, como se refleja en el siguiente cuadro comparativo:

\begin{tabular}{|c|c|c|c|c|c|}
\hline & $\begin{array}{l}\text { Elección y } \\
\text { duración }\end{array}$ & $\begin{array}{l}\text { Independencia } \\
\text { y cese }\end{array}$ & Potestades & Garantía subjetiva & $\begin{array}{l}\text { Garantía } \\
\text { objetiva }\end{array}$ \\
\hline $\begin{array}{l}\text { ASTURIAS } \\
\text { (Ley 1/1992) }\end{array}$ & $\begin{array}{l}\text { Por el } \\
\text { Consejero de } \\
\text { Sanidad, } \\
\text { según terna } \\
\text { del Consejo } \\
\text { de Salud, por } \\
\text { cuatro años }\end{array}$ & $\begin{array}{l}\text { Se proclama } \\
\text { su "plena } \\
\text { autonomía e } \\
\text { independencia" } \\
\text { pero no se } \\
\text { impide su cese }\end{array}$ & $\begin{array}{l}\text { Se reconoce } \\
\text { potestad } \\
\text { inspectora en } \\
\text { sentido débil }\end{array}$ & $\begin{array}{l}\text { Sólo se prevé la } \\
\text { propuesta de } \\
\text { instrucción de } \\
\text { información } \\
\text { reservada o } \\
\text { expediente } \\
\text { sancionador }\end{array}$ & $\begin{array}{l}\text { Memoria } \\
\text { anual, sin } \\
\text { indicarse } \\
\text { expresamente } \\
\text { que puede } \\
\text { contener } \\
\text { sugerencias }\end{array}$ \\
\hline $\begin{array}{l}\text { BALEARES } \\
\text { (Ley 5/2003) }\end{array}$ & $\begin{array}{l}\text { Por el } \\
\text { Gobierno de } \\
\text { Baleares, oído } \\
\text { el Consejo de } \\
\text { Salud, por } \\
\text { cinco años }\end{array}$ & $\begin{array}{l}\text { Se proclama } \\
\text { su "autonomía } \\
\text { funcional" } \\
\text { pero no se } \\
\text { impide su cese }\end{array}$ & $\begin{array}{l}\text { No se } \\
\text { reconoce } \\
\text { expresamente } \\
\text { potestad } \\
\text { inspectora }\end{array}$ & $\begin{array}{l}\text { Sólo se prevé la } \\
\text { propuesta al } \\
\text { Consejo de Salud } \\
\text { de exigencia de } \\
\text { responsabilidad } \\
\text { administrativa }\end{array}$ & $\begin{array}{l}\text { Puede } \\
\text { formular } \\
\text { sugerencias y } \\
\text { debe dar } \\
\text { cuentas } \\
\text { anualmente }\end{array}$ \\
\hline $\begin{array}{l}\text { CASTILLA-LA } \\
\text { MANCHA } \\
(\text { Ley 8/2000) }\end{array}$ & $\begin{array}{l}\text { Por las Cortes } \\
\text { Regionales, } \\
\text { por seis años }\end{array}$ & $\begin{array}{l}\text { Se proclama } \\
\text { su "plena } \\
\text { autonomía e } \\
\text { independencia" } \\
\text { y se prohíbe su } \\
\text { cese } \\
\text { discrecional }\end{array}$ & $\begin{array}{l}\text { Se reconoce } \\
\text { potestad } \\
\text { inspectora en } \\
\text { sentido fuerte }\end{array}$ & $\begin{array}{l}\text { No hay } \\
\text { previsiones }\end{array}$ & $\begin{array}{l}\text { Memoria } \\
\text { anual, sin } \\
\text { indicarse } \\
\text { expresamente } \\
\text { que puede } \\
\text { contener } \\
\text { sugerencias }\end{array}$ \\
\hline
\end{tabular}




\begin{tabular}{|c|c|c|c|c|c|}
\hline $\begin{array}{l}\text { EXTREMADURA } \\
\text { (Ley 10/2001) }\end{array}$ & $\begin{array}{l}\text { Por el } \\
\text { Gobierno de } \\
\text { Extremadura, } \\
\text { a propuesta } \\
\text { del Consejo } \\
\text { Regional de } \\
\text { Consumidores } \\
\text { y Usuarios, } \\
\text { por cinco años }\end{array}$ & $\begin{array}{l}\text { Se proclama su } \\
\text { "plena } \\
\text { autonomía e } \\
\text { independencia" } \\
\text { pero no se } \\
\text { impide su cese }\end{array}$ & $\begin{array}{l}\text { No se } \\
\text { reconoce } \\
\text { expresamente } \\
\text { potestad } \\
\text { inspectora }\end{array}$ & $\begin{array}{l}\text { Sólo se prevé la } \\
\text { propuesta al } \\
\text { órgano } \\
\text { competente de } \\
\text { exigencia de } \\
\text { responsabilidad } \\
\text { administrativa }\end{array}$ & $\begin{array}{l}\text { Dación anual } \\
\text { de cuentas, } \\
\text { sin indicarse } \\
\text { expresamente } \\
\text { que puede } \\
\text { presentar } \\
\text { sugerencias }\end{array}$ \\
\hline $\begin{array}{l}\text { LA RIOJA } \\
\text { (Ley 2/2002) }\end{array}$ & $\begin{array}{l}\text { Por el } \\
\text { Gobierno de } \\
\text { La Rioja, a } \\
\text { propuesta del } \\
\text { Consejero de } \\
\text { Salud, sin } \\
\text { plazo. }\end{array}$ & $\begin{array}{l}\text { Se proclama su } \\
\text { "plena } \\
\text { autonomía e } \\
\text { independencia" } \\
\text { pero no se } \\
\text { impide su cese }\end{array}$ & $\begin{array}{l}\text { Se reconoce } \\
\text { potestad } \\
\text { sancionadora } \\
\text { en sentido } \\
\text { fuerte }\end{array}$ & $\begin{array}{l}\text { La Administración } \\
\text { está obligada a } \\
\text { tener en cuenta } \\
\text { los "informes y } \\
\text { recomendaciones" } \\
\text { del Defensor }\end{array}$ & $\begin{array}{l}\text { Memoria } \\
\text { anual, que } \\
\text { puede incluir } \\
\text { sugerencias }\end{array}$ \\
\hline $\begin{array}{l}\text { MADRID } \\
\text { (Ley 12/2001) }\end{array}$ & $\begin{array}{l}\text { Por el } \\
\text { Presidente de } \\
\text { la Comunidad; } \\
\text { a propuesta } \\
\text { del Consejero } \\
\text { de Sanidad, } \\
\text { sin plazo }\end{array}$ & $\begin{array}{l}\text { Se califica de } \\
\text { “órgano } \\
\text { independiente } \\
\text { en el seno de la } \\
\text { Consejería de } \\
\text { Sanidad pero } \\
\text { no se impide } \\
\text { su cese }\end{array}$ & $\begin{array}{l}\text { Se reconoce } \\
\text { potestad } \\
\text { sancionadora } \\
\text { en sentido } \\
\text { débil }\end{array}$ & $\begin{array}{l}\text { La Administración } \\
\text { está obligada a } \\
\text { tener en cuenta } \\
\text { los “comentarios, } \\
\text { informes y } \\
\text { recomendaciones” } \\
\text { del Defensor }\end{array}$ & $\begin{array}{l}\text { Memoria } \\
\text { anual, que } \\
\text { puede incluir } \\
\text { sugerencias }\end{array}$ \\
\hline
\end{tabular}

Centrándonos en el aspecto que más nos interesa, la garantía subjetiva del derecho a la salud, observamos notables limitaciones en la configuración del órgano en Castilla-La Mancha (donde la ley guarda silencio al respecto) y en Asturias, Baleares y Extremadura, pues en estas tres últimas Comunidades el resultado del juicio negativo de la actuación administrativa se circunscribe a proponer la apertura de un posible expediente sancionador, que sólo abarca una pequeña parte de las posibles vulneraciones del derecho, no resultando previsible que llegue a buen término. Por el contrario, las leyes de La Rioja y Madrid resultan más acertadas, configurando un órgano con mayores posibilidades de actuación, claramente inspiradas en la figura del Defensor del Pueblo.

En todo caso, las acentuadas disparidades en la regulación autonómica de las vías extrajudiciales de reclamación no han de llevar, necesariamente, a diferencias sustanciales de protección, pues todo dependerá de la voluntad política de atender las reclamaciones, siendo para ello indiferente si son tramitadas por un centro hospitalario o por una institución ad hoc.

En otro orden de cosas, puede reclamarse contra los incumplimientos administrativos del derecho a la salud ante el Defensor del Pueblo o sus homólogos autonómicos ${ }^{34}$. Como hemos comprobado, a título de ejemplo, mediante referencias anteriores a

\footnotetext{
${ }^{34}$ Está por ver cómo se coordina su actuación con la propia de los Defensores del paciente en las seis Comunidades Autónomas recién citadas (cuestión aludida sólo en Asturias, donde se obliga al Defensor de los Usuarios a prestar colaboración y apoyo al Defensor del Pueblo), problema que se complica en las que cuentan con Defensor autonómico (Asturias y Castilla-La Mancha).
} 
algunas actuaciones del Defensor del Pueblo de España, estos órganos han desempeñado una eficaz tarea en la garantía, subjetiva y objetiva, del derecho a la salud ${ }^{35}$.

\section{CONTROL JUDICIAL DE LA ADMINISTRACIÓN}

La garantía más intensa de protección de los derechos fundamentales, la vía judicial, también resulta aplicable, como es obvio, al derecho a la salud (si no, no podría hablarse de derecho como tal), si bien con limitaciones importantes (más fácticas que jurídicas), a las que seguidamente haremos mención.

El reparto de competencias se realiza todavía entre la jurisdicción social y la contencioso-administrativa, desde una discutible interpretación del concepto de “Seguridad Social” de los artículos 9.5 LOPJ y 2 b) LPL. Sin embargo, la tendencia lógica es la progresiva concentración del control judicial de la Administración sanitaria en la justicia contencioso-administrativa, y a esta última dedicaremos las líneas que siguen (sin perjuicio de su aplicación, mutatis mutandis, a la justicia social) ${ }^{36}$.

Con carácter previo, se plantea el problema del acceso a la jurisdicción, debiendo remitirnos al efecto al artículo 19.1 LJCA, que concede legitimación a "las personas físicas o jurídicas que ostenten un derecho o interés legítimo”, así como a "las corporaciones, asociaciones, sindicatos y grupos [...] que resulten afectados o estén legalmente habilitados para la defensa de los derechos e intereses legítimos colectivos”. En nuestro ordenamiento no están previstas las acciones colectivas en materia de salud, lo que exige una interpretación generosa del precepto citado (algo impuesto, por otra parte, por el art. $43.1 \mathrm{CE}$ ), a fin de posibilitar la apertura del proceso a solicitud de personas no individuales ${ }^{37}$ : si los problemas son generales (piénsese sobre todo en el incumplimiento del elemento de disponibilidad del derecho), las soluciones también deberán serlo. En otro orden de cosas, resulta criticable el déficit de legitimación del Ministerio Fiscal y del Defensor del Pueblo para recurrir frente a vulneraciones generales de los derechos sociales.

${ }^{35}$ Para una síntesis de las actuaciones del Defensor del Pueblo de España remitimos a la aportación de Fernando Benito en FEDERACIÓN IBEROAMERICANA DE OMBUDSMAN, IV Informe sobre Derechos Humanos: Protección de la salud, Trama, Madrid, 2006, pp. 465-474. Disponible en http://www.portalfio.org/inicio/content/view/13/28/.

36 Excepcionalmente, el Tribunal Constitucional ha admitido alegaciones del derecho a la salud (recordemos que el art. 43.1 CE queda fuera del recurso de amparo) por la vía del art. 15 CE (derecho a la vida e integridad). En efecto, inspirándose en el Tribunal Europeo de Derechos Humanos, el Tribunal Constitucional ha señalado que "el derecho a la salud o, mejor aún, el derecho a que no se dañe o perjudique la salud personal, queda comprendido en el derecho a la integridad personal del artículo 15 CE, si bien no todo supuesto de riesgo o daño para la salud implica una vulneración del derecho fundamental a la integridad física y moral, sino tan sólo aquél que genere un peligro grave y cierto para la misma” (SSTC 35/1996, 119/2001, 5/2002, 62/2007 y 160/2007). Téngase en cuenta que, si no se diera el obstáculo formal de la exclusión del art. 43.1 del recurso de amparo, lo correcto hubiera sido proteger estas situaciones por la vía del derecho a la salud y no por la vía del derecho a la vida e integridad. Dada la "función educadora” de esta doctrina sobre los tribunales ordinarios, no tengo nada que objetar, pero estos últimos, no condicionados ya por el mencionado obstáculo formal, deberían ya razonar sin problema a partir del art. 43.1.

${ }^{37}$ Ello no implica, obviamente, que deba concederse legitimación activa a cualquier ciudadano, como con acierto se razona en la STSJ de la Comunidad Valenciana de 26 de octubre de 2001. En contraste, sobre un ámbito próximo al derecho a la salud, vid. las también correctas SSTS de 16 y 23 de enero de 1998, que admiten la legitimación de diversas asociaciones para recurrir el reglamento de acreditación de centros sanitarios para la práctica legal de la interrupción voluntaria del embarazo. 
Una vez abierto el proceso, lo que va a discutirse es si hubo o no una intervención sobre el derecho a la salud ${ }^{38} \mathrm{y}$, en caso afirmativo, si la intervención fue o no legítima; en este último caso, hubo vulneración del derecho, lo que debería dar lugar a una sentencia estimatoria, con el contenido que después veremos.

Los tipos de pretensiones (y, correlativamente, de futuras sentencias) de tutela de la faceta prestacional del derecho a la salud ${ }^{39}$ son sobre todo dos:

a) Los incumplimientos del derecho a la asistencia sanitaria o al medicamento pueden adoptar formas jurídicas diversas, que van desde la total omisión fáctica hasta la producción de un acto administrativo formalizado. A mi entender, todas estas intervenciones tienen cabida en el proceso contencioso-administrativo, si bien el objeto del recurso será en cada caso, obviamente, diferente.

En síntesis, podemos reclamar (y obtener) de la justicia contencioso-administrativa tres grandes tipos de resultados, entre otros posibles: la obligación de la Administración de aumentar o mejorar los servicios sanitarios disponibles, la obligación del personal sanitario de otorgar una determinada prestación y la indemnización en caso de daños (inclusive los morales) derivados del funcionamiento de la Administración sanitaria. Este último tipo de supuestos es el que acapara la práctica totalidad de las decisiones judiciales sobre el derecho a la salud, aunque este apenas sea citado expresamente. Como después reiteraré, ambas circunstancias son reveladoras de un déficit grave del sistema de garantía judicial del derecho a la salud en España, que no es exclusivo de esta figura: a los tribunales no llegan los problemas importantes, y cuando llegan, la jurisdicción evita guiar su razonamiento en una perspectiva de derechos fundamentales.

No puedo siquiera sintetizar la amplia y casuística jurisprudencia sobre la responsabilidad patrimonial de la Administración sanitaria, remitiéndome in totum a otro trabajo anterior ${ }^{40}$. Como aspecto positivo a resaltar, baste con apuntar aquí que de esa copiosa jurisprudencia se deriva, como efecto reflejo (si hay obligación de indemnizar es porque previamente alguien incumplió un deber jurídico), una configuración bastante exigente del contenido del derecho a la salud exigible a la Administración en general y al personal sanitario en particular.

b) La denegación del derecho a la salud a un titular del mismo (circunstancia normalmente reconducible a la desigualdad de trato) puede ser también denunciada ante la justicia contencioso-administrativa, pudiendo solicitarse ante esta, según los casos, la anulación del acto discriminatorio o la puesta en práctica de una actuación dirigida a paliar la desigualdad acaecida.

\footnotetext{
${ }^{38}$ En la lógica tradicional de la justicia revisora y liberal (en ambos casos, control de acciones), raramente van a calificarse de intervenciones las omisiones o los riesgos de intervención: una nueva muestra de las dificultades de proteger adecuadamente la faceta prestacional del derecho a la salud en el marco judicial.

${ }^{39}$ Nos centramos seguidamente en los casos de alegación directa del derecho a la salud. No se olvide que este derecho puede también protegerse en sede judicial mediante la interpretación (alegación indirecta, si se quiere) en muchos otros casos (p. ej., la salud como límite de derechos de defensa o la vulneración de las garantías de información o participación).

${ }^{40}$ G. ESCOBAR ROCA, "Derecho a la salud y responsabilidad de la Administración sanitaria”, Revista de Responsabilidad Civil, Circulación y Seguro, n ${ }^{\circ}$ 9, 2007, pp. 4 y ss. y la doctrina y jurisprudencia allí citadas.
} 
En los dos supuestos, de llegarse a la conclusión de que se vulneró el derecho a la salud, la sentencia estimatoria debe contener el fallo previsto en el artículo 71 LJCA, que otorga gran flexibilidad a los jueces y tribunales ${ }^{41}$, los cuales pueden imponer a la Administración la emisión o anulación de un acto (p. ej., un reintegro de gastos sanitarios) o la práctica (p. ej., la dotación de determinados medios en un hospital o la prestación de un concreto tratamiento sanitario), modificación o cese de una actuación (p. ej., la autorización otorgada a una empresa que provoca daños a la salud), incluso fijando plazos para el cumplimiento del fallo (con las consecuencias del art. 112 LJCA), cuestión esta última especialmente importante en materia de salud. En cuanto a la prohibición, dirigida a los tribunales, de "determinar el contenido discrecional de los actos anulados” (por olvido, el art. 71 nada dice sobre la discrecionalidad de la actividad administrativa que en su caso se imponga), creo que debe ser interpretada muy matizadamente, pues habrá casos en los que apenas quede margen para la discrecionalidad administrativa ${ }^{42}$, bastante limitada, recordemos, cuando de derechos fundamentales se trata.

Con carácter general, además del acceso a la jurisdicción, ya aludido, los principales problemas que plantea la garantía del derecho a la salud en el proceso contencioso-administrativo (similares a los planteados en general por los derechos sociales) son los siguientes:

a) La necesidad de resoluciones judiciales rápidas, dada la peculiar naturaleza del bien jurídico afectado: en la mayoría de los casos, una tutela tardía de la salud resultará una tutela inútil. A estos efectos, la tardanza en dictar sentencia por los órganos de la justicia contencioso-administrativa, se revela claramente inconstitucional; no se trata, evidentemente, de un problema del derecho a la salud, sino de un mal endémico de la justicia contencioso-administrativa española, que no corresponde abordar aquí. Por otra parte, la posibilidad de solicitar "en cualquier estado del proceso la adopción de cuantas medidas aseguren la efectividad de la sentencia” (art. 129.1 LJCA) queda diluida en el resto de la regulación legal de las medidas cautelares, marcada todavía por la perspectiva de una justicia predominantemente revisora, de corte liberal. En todo caso, la práctica habitual de los tribunales es reacia a la imposición de medidas cautelares en general y, sobre todo, de medidas cautelares de contenido positivo.

b) Frecuentemente, la dificultad de demostrar en cada caso que una determinada acción (y lo que será más frecuente, omisión) de la Administración daña o no protege suficientemente la salud. En muchas ocasiones, esta demostración depende de informes técnicos, que quedan fuera del contenido del derecho a la asistencia jurídica gratuita, lo que potencia la desigualdad material de las partes, ya de por sí frecuente

\footnotetext{
${ }^{41}$ Lamentablemente, nuestros jueces no suelen ser demasiado imaginativos al respecto, cuando la tutela del derecho a la salud bien requeriría soluciones que se apartaran de los fallos tradicionales, excesivamente marcados todavía, a nuestro juicio, por la impronta revisora, más propia de la óptica liberal.

${ }^{42}$ Vid., al respecto, las lúcidas reflexiones de V. ABRAMOVICH y C. COURTIS, Los derechos sociales..., cit., pp. 138-160), en torno a seis ejemplos de fallos judiciales estimatorios de demandas de protección del derecho a la salud. En todos los casos analizados el margen otorgado a la discrecionalidad administrativa fue mínimo.
} 
en la defensa en juicio de los derechos sociales. Como estrategia procesal y hasta tanto no se amplíe el ámbito legal de la justicia gratuita, se propone, por un lado, aprovechar los datos obrantes en las propias Administraciones públicas, y, por otro, recabar el apoyo técnico de asociaciones sin afán de lucro.

c) La necesidad de un seguimiento de la ejecución de las sentencias que estimen la vulneración de la faceta prestacional del derecho a la salud. Tal y como también sucede en relación con otros derechos sociales, pese a la vía abierta por el artículo 108.1 LJCA, en España apenas hay práctica judicial de vigilancia, en diálogo con la Administración, de la ejecución de este tipo de sentencias. Al respecto, me permito proponer una estrategia procesal de subversión de estas inercias, intentando transformar las habilitaciones del precitado artículo 108.1 en obligaciones del juez. Los problemas más graves se van a plantear en relación con las obligaciones personalísimas (esto es, aquellas que sólo pueden ser cumplidas por la Administración condenada), que son sobre todo las que incumben al elemento de disponibilidad del derecho, desde una perspectiva general; incluso en estos casos, siempre quedará, como posibilidad extrema, la deducción de testimonio para la exigencia de la responsabilidad dimanante del artículo 410 CP. Téngase en cuenta que la mayor parte de las obligaciones que encontraremos en los fallos estimatorios van a ser no personalísimas, por lo que resulta posible que el juez imponga la ejecución subsidiaria (p. ej., el tratamiento sanitario en un centro privado) con cargo a la Administración condenada.

Los tres problemas referidos, y sobre todo, la lentitud, carestía y formalismo del proceso contencioso-administrativo, motivan la escasa tradición de protección judicial del derecho a la salud en España: como hemos venido señalando, la práctica totalidad de las sentencias sobre su aplicación directa se refieren a dos cuestiones muy concretas, ambas de escaso contenido garantista, el reintegro de gastos ocasionados en la sanidad privada (que afecta a la gratuidad, no a la asistencia en sí misma) y la responsabilidad patrimonial de la Administración sanitaria (que llega tarde, cuando se ha producido un daño). Hasta tanto la situación actual se subvierta (lo que no parece fácil, pues deriva de problemas estructurales), no nos queda sino recomendar la potenciación de las vías extrajudiciales de reclamación aludidas en el apartado precedente.

\section{PROTECCIÓN CIVIL Y PENAL}

Cuando cualquier persona provoca daños a la salud de otra entra en juego el sistema ordinario de responsabilidad civil, que puede ser extracontractual (art. 1902 CC) o, lo que será más frecuente (pues son los profesionales sanitarios los autores típicos de este tipo de daños), contractual y, dentro de esta, como norma general, de incumplimiento de obligaciones de medios (contrato de servicios) o, excepcionalmente, de obligaciones de resultado (contrato de obra). La doctrina y jurisprudencia sobre la responsabilidad civil sanitaria es amplísima, no pudiendo entrar aquí siquiera en una síntesis de la misma, por exceder esta temática de lo propiamente constitucional.

Como cierre del sistema nacional de garantías del derecho a la salud, el Código Penal protege, directa o indirectamente, este bien jurídico, mediante los grupos delictivos siguientes: 
a) Los delitos de lesiones (arts. 147-156) protegen frente al menoscabo de la integridad corporal o la salud física o mental de toda persona, sirviendo por tanto de garantía del derecho a la salud como derecho reaccional. El tipo básico, que lleva aparejada la pena de prisión de seis meses a tres años, castiga la producción de lesiones que requieran "objetivamente para su sanidad, además de una primera asistencia facultativa, tratamiento médico o quirúrgico”.

b) El delito de omisión del deber de socorro castiga con multa de tres a doce meses a quien "no socorriere a una persona que se halle desamparada y en peligro manifiesto y grave, cuando pudiere hacerlo si riesgo propio ni de terceros” (art. 195). Por su parte, según el artículo 196, el "profesional que, estando obligado a ello, denegase asistencia sanitaria o abandonare los servicios sanitarios, cuando de la denegación o abandono se derive riesgo grave para la salud de las personas, será castigado con las penas del artículo precedente en su mitad superior y con la de inhabilitación especial para empleo o cargo público, profesión u oficio, por tiempo de seis meses a tres años”. El delito del artículo 196 CP, que protege a todos los titulares del derecho ${ }^{43}$, pone en manos de estos un arma fundamental para su defensa en los casos de incumplimiento por los profesionales sanitarios de sus obligaciones de cumplimiento del derecho a la salud.

c) Los delitos contra la salud pública, que garantizan objetivamente la salud individual, castigan con diversos grados de prisión y otras penas accesorias la elaboración, venta y suministro de todo tipo de sustancias nocivas para la salud: a un tipo básico (arts. 359-360) se suman tipos especiales sobre medicamentos (arts. 361-362), productos alimentarios (arts. 363-367) y drogas tóxicas, estupefacientes o sustancias psicotrópicas (arts. 368-378).

\section{GARANTÍAS INTERNACIONALES}

En el ámbito internacional, la protección del derecho a la salud se concentra en la garantía objetiva del derecho, mediante dos técnicas fundamentales, no desconocidas en el ámbito interno:

a) El diseño y ejecución de una amplia política de salud pública, por parte sobre todo de la Organización Mundial de la Salud y de la Unión Europea ${ }^{44}$. Las técnicas utilizadas son muy variadas y cuentan con grados también muy distintos de vinculación jurídica, pudiendo llegar incluso a normas que prevalecen sobre el Derecho interno y a órdenes coercitivas que se imponen a los poderes públicos españoles. Estas políticas favorecen ampliamente el derecho a la salud, por cuanto contribuyen de manera decisiva a evitar la aparición y propagación de muchas enfermedades.

b) La obligación del Estado español de presentar informes sobre la situación (y evolución, con respecto a la situación anterior) del derecho a la salud (entre otros derechos sociales), ante organismos internacionales, como el CDESC o el Comité

\footnotetext{
${ }^{43}$ La obligación a la que se refiere el precepto es el correlato del derecho a la salud, no de su gratuidad. 44 Para una panorámica general, vid. la contribución de Ana Salado en FEDERACIÓN IBEROAMERICANA DE OMBUDSMAN, IV Informe..., cit., pp. 30-50 y 123-139, así como C. CIERCO SEIRA, Administración..., cit., pp. 90-117.
} 
Europeo de Derechos Sociales, entre otros. La respuesta de estos organismos a los datos enviados por España sobre el derecho a la salud es muy escueta y, en todo caso, apenas ha calado en la opinión pública española. Por ello, la utilidad de esta técnica de garantía es muy escasa.

Por otra parte, de manera casi anecdótica, se abre a los ciudadanos la posibilidad de acudir a organismos internacionales en defensa de su derecho subjetivo a la salud, una vez agotadas las vías previstas en el Derecho interno:

a) En el ámbito de Naciones Unidas, pueden presentarse quejas individuales ante los Comités correspondientes por vulneración de los artículos 5 e) de la Convención Internacional sobre la Eliminación de todas las Formas de Discriminación Racial y 11.1 f) y 12 de la Convención sobre la Eliminación de todas las Formas de Discriminación contra la Mujer. Igualmente, pueden presentarse quejas individuales ante el Comité de Derechos Humanos, si bien no alegando directamente el derecho a la salud (que, como tal, no está reconocido en el Pacto de Derechos Civiles y Políticos $^{45}$ ), sino otros derechos relacionados con él ${ }^{46}$.

b) En el ámbito del Consejo de Europa, pueden presentarse demandas ante el TEDH, alegando derechos conexos al derecho a la salud ${ }^{47}$ y quejas colectivas (por organizaciones gubernamentales y no gubernamentales) ante el Comité Europeo de Derechos Sociales, en este caso por vulneración de los artículos 11 y 13 de la Carta Social Europea.

c) En el ámbito de la Unión Europea, los ciudadanos tienen muy limitado, como es sobradamente conocido, el acceso a los recursos. En algunos casos sus pretensiones de tutela del derecho a la salud se han visto satisfechas gracias al planteamiento por los tribunales nacionales de una cuestión prejudicial ante el TJCE; sin embargo, las limitaciones de esta vía para la tutela del derecho subjetivo son evidentes, sobre todo si tenemos en cuenta que en España la negativa de un juez a plantear una cuestión prejudicial no implica vulneración del artículo $24.1 \mathrm{CE}^{48}$.

${ }^{45}$ Así, Comunicación sobre el caso Eugene Linder contra Finlandia, de 23 de noviembre de 2005.

${ }^{46}$ P. ej., Comunicaciones sobre los casos Toonen contra Austria, de 4 de abril de 1994; Marcel Mulezzi contra República Democrática del Congo, de 23 de julio de 2004; o Bozena Fijalkowska contra Polonia, de 4 de agosto de 2005.

${ }^{47}$ Sobre el art. 2 CEDH (derecho a la vida), vid. las SSTEDH Oneryildiz contra Turquía, de 18 de junio de 2002 (Sala) y 30 de noviembre de 2004 (Gran Sala). En D contra Reino Unido, de 2 de mayo de 1997, se consideró vulnerado el art. 3 CEDH (prohibición de la tortura) por deportar las autoridades británicas a un ciudadano a su país de origen, Saint Kitts, donde no tenía garantizado el tratamiento médico de la enfermedad que padecía; y a la misma conclusión se llegó en Melnik contra Ucrania, de 28 de febrero de 2006, por la falta de adecuada asistencia contra la tuberculosis a un condenado en prisión. En la STEDH Noveselov contra Rusia, de 3 de junio de 2005, las condiciones materiales de la detención se declararon insalubres. Por su parte, en la STEDH Fadeyeva contra Rusia, de 10 de junio de 2005, se consideró que los altos niveles de polución, que afectaban a la salud de la demandante, vulneraron su derecho a la vida privada (art. $8 \mathrm{CEDH})$, al llegar la contaminación hasta su domicilio.

${ }^{48}$ STC 201/1996. 